\title{
Apparatus for Combined Static and Dynamic Uniaxial Stress
}

\section{Balslev, I.}

\section{Published in:}

Review of Scientific Instruments

Link to article, DOI:

10.1063/1.1720582

Publication date:

1967

Document Version

Publisher's PDF, also known as Version of record

Link back to DTU Orbit

Citation (APA):

Balslev, I. (1967). Apparatus for Combined Static and Dynamic Uniaxial Stress. Review of Scientific Instruments, 38(10), 1528-1529. https://doi.org/10.1063/1.1720582

\section{General rights}

Copyright and moral rights for the publications made accessible in the public portal are retained by the authors and/or other copyright owners and it is a condition of accessing publications that users recognise and abide by the legal requirements associated with these rights.

- Users may download and print one copy of any publication from the public portal for the purpose of private study or research.

- You may not further distribute the material or use it for any profit-making activity or commercial gain

- You may freely distribute the URL identifying the publication in the public portal

If you believe that this document breaches copyright please contact us providing details, and we will remove access to the work immediately and investigate your claim. 
result in a brighter image. In this system, a larger mirror resulted in a blurred image due to multiple reflections.

The author would like to thank M. Buckly for assistance with the glass blowing and D. E. Moran for assistance with the drafting.

* Taken in part from research supported by ONR contract Nonr 233 (48).

+ Present address: California State College at Fullerton, Fullerton, Calif. 92631.

${ }_{1}^{1}$ M. Bodenstein and W. Dux, Z. Phys. Chem. (Leipzig) 85, 297 (1913).

2 S. G. Yorke, J. Sci. Instr. 22, 196 (1945).

\section{Small Conductor Vacuum Feedthrough*}

\author{
A. DiGiallonardo \\ The Dow Chemical Company, Rocky Flats Division, \\ Golden, Colorado 80401
}

(Received 29 May 1967)

A FITTING of Swagelok ${ }^{1}$ type has been used to make a high vacuum feedthrough for small conductors. A cross section drawing is shown in Fig. 1. The seal is made by compressing an insert of Teflon ${ }^{2}$ plastic, fitted into the Swagelok fitting, onto the wire or rod which forms the conductor of the feedthrough. The insert is machined to fit snugly into the Swagelok fitting. A hole is drilled through the insert to accommodate the conductor. This hole is drilled only large enough to allow minimum clearance for the passage of the conductor. When the conductor is in place, the Swagelok is tightened on the Teflon insert, as recommended by the manufacturer. This compresses the insert between the fitting and the conductor, thus forming the seal.

The Swagelok fitting can be mounted on any style and any size flange. Mounting can be done by any means appropriate to good vacuum technique. The feedthroughs made in our Laboratory were mounted on blank shear seal flanges which were drilled and threaded to receive the threads of the fittings. Teflon tape was used on the threads to provide a vacuum seal. Nonthreaded fittings could be used by welding or hard soldering them to the flange.

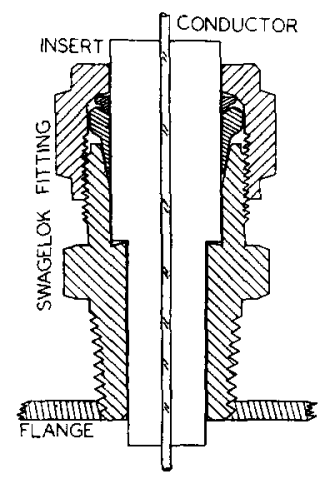

Fig. 1. Cross section of the feedthrough.
Feedthroughs of this type have been found to be very useful for providing entrance of thermocouples into vacuum chambers and have been used with vacuum in the $10^{-8}$ Torr range. In most cases, $0.76 \mathrm{~mm}$ wire has been used, but reliable seals have been made with smaller or larger single strand wire. Braided wire made unreliable seals.

* Work performed under USAEC Contract No. AT (29-1)-1106.

${ }^{1}$ Swagelok is a registered trademark of the Crawford Fitting Co., 29500 Solon Rd., Solon, Ohio.

${ }^{2}$ Teflon is a registered trademark of E. I. duPont de Nemours \& Co.

\section{Apparatus for Combined Static and Dynamic Uniaxial Stress}

\author{
I. BALSLEV* \\ Physics Laboratory III, Technical University of Denmark, \\ Lyngby, Denmark
}

(Received 3 May 1967; and in final form, 9 June 1967)

THE remarkable sensitivity of optical measurements on dynamically strained crystals was demonstrated independently by Gobeli and Kane ${ }^{1}$ and by Engeler et al. ${ }^{2}$ These authors used techniques without the possibility of superimposing a static component of the stress. This letter reports on an apparatus for combined static and dynamic uniaxial stress. Piezo-optical measurements with this setup have been reported. ${ }^{3,4}$

The design is based on a previously described apparatus ${ }^{5}$ for static compressive stress modified to permit magnetic generation of a sinusoidally modulated force. Figure 1 shows the modified stressing frame. The sample with dimensions approximately $1 \times 1 \times 15 \mathrm{~mm}$ is cemented into two rods, the upper rod being fixed and the lower guided by four bronze blade springs that assure negligible friction. These blades replace the piston formerly used. ${ }^{5}$ The

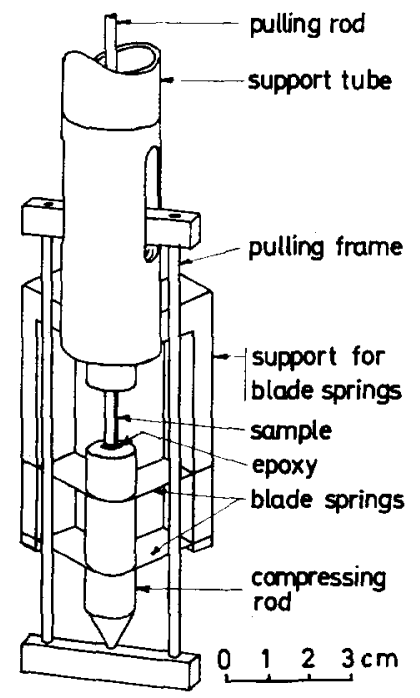

FIG. 1. Strain apparatus for compressive uniaxial stress with negligible friction in guiding arrangement. The two orthogonal pairs of blade springs are made of $0.3 \mathrm{~mm}$ bronze. 


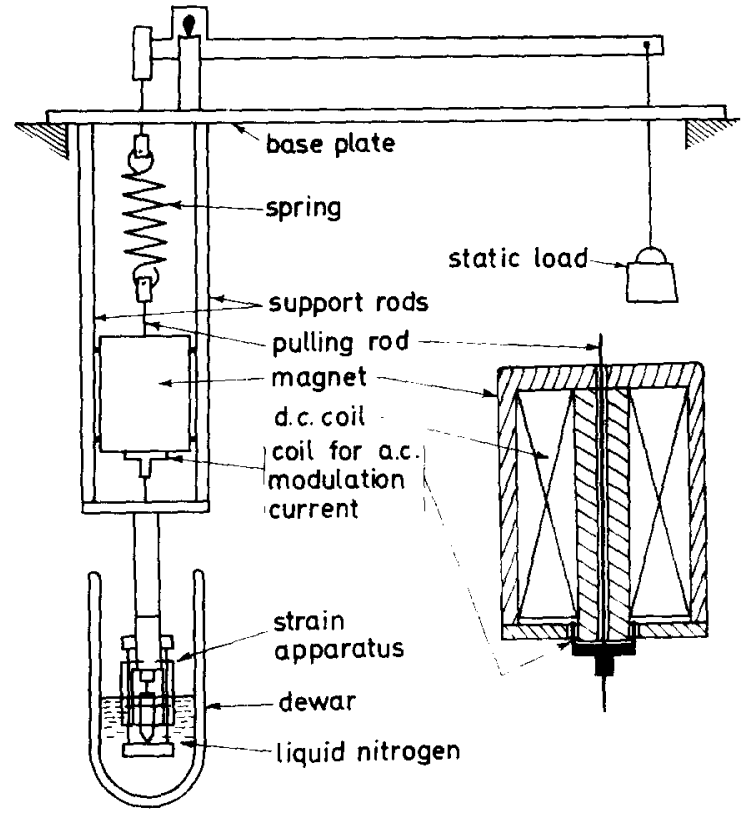

Fig. 2. Load arrangement for application of combined static and dynamic force to the pulling rod.

lower compressing rod is pulled upwards by a frame and a pulling rod. In Fig. 2 is shown the arrangement for applying a combined static and dynamic force. The magnet gives a constant, radial magnetic field in an annular volume as in a loudspeaker, and the force modulation coil for ac is rigidly connected to the pulling rod. The static load is transfered to this rod through a heavy spring preventing an oscillatory motion of load and arm.

Typical data of operation are static force 0 to $100 \mathrm{kgf}$, dynamic force 0 to $5 \mathrm{kgf}$ peak to peak, and modulation frequency $70 \mathrm{cps}$.

The apparatus may be operated at liquid nitrogen temperatures as indicated in Fig. 2. Temperatures of the sample very close to $77^{\circ} \mathrm{K}$ were obtained by means of a container with liquid nitrogen (not shown) soldered to the cylindrical piece between support tube and sample (see Fig. 1).

The technique reported here may be useful in investigations of any piezo-effect (electrical or optical) where a differential modulation of the stress is desired. Such situations arise if the change due to stress of an observable quantity is smaller than the long term stability of the experimental setup, but larger than the fundamental noise (e.g., dark noise of the detector in optical measurements).

Thanks are due to T. Guldbrandsen and I. Trabjerg for valuable discussions.

* On leave of absence at Bell Telephone Laboratories, Murray Hill, New Jersey.

${ }^{1}$ G. W. Gobeli and E. O. Kane, Phys. Rev. Letters 15, 142 (1965).

${ }^{2}$ W. E. Engeler, H. Fritzsche, M. Garfinkel, and J. J. Tiemann, Phys. Rev. Letters 14, 1069 (1965).

\& I. Balslev, Phys. Letters 24A, 113 (1967).

* I. Balslev, Solid State Commun. 5, 315 (1967).

${ }^{6} \mathrm{I}$. Balslev, Phys. Rev. 143, 636 (1966).

\section{Simple Method of Rotating Samples in Microwave Cavities at Low Temperatures}

\author{
H. VAN DEN BOOM \\ Philips Research Laboratories, N. V. Philips' Gloeilampenfabrieken, \\ Eindhoven, Netherlands
}

(Received 24 April 1967; and in final form, 12 June 1967)

BOR OR EPR measurements it is sometimes necessary to arbitrarily position a sample in a microwave cavity at low temperature with respect to the magnetic field. When the magnet has a rotating base, it is possible to rotate the magnetic field around the sample in a horizcntal plane. When the crystal axes are unknown, this method is not adequate because there is still one degree of freedom left. We have therefore developed a method for rotating a sample in a vertical plane at low temperatures.

In order to cancel out unwanted modes, a flattened version of a cylindrical cavity of the $\mathrm{TE}_{112}$ mode has been chosen. Matching is achieved by the use of a Teflon variable coupler (B), as described by Gordon. ${ }^{1}$ In the broad sides, slots (C) have been made through which a Teflon cogwheel (D) can be driven by a brass worm-gear (E), which has been mounted outside the cavity (A).

The cog-wheel (D) drives a Teflon-shaft $(F)$ on which the sample under investigation can be mounted (see Fig. 1). Penetration of liquid helium into the cavity is prevented by sealing the whole assembly by means of a brass pot $(\mathrm{J})$, which fits very closely around the brass manifold (K). High vacuum silicon grease (Dow Corning Corp.) is used between them in order to achieve a good seal. In order to drive the wormgear-shaft outside the helium bath with-

Fig, 1. Exploded view of microwave cavity assembly. A-lower part of microwave cavity; $B$-Teflon variable coupler; C--slots in cavity walls; D-Teflon cogwheel; E-brass wormgear; F-Teflon shaft; G-sample mount; I-iris; Jbrass pot; $\mathrm{K}$-brass manifold; $\mathrm{L}$-waveguide; and $M$-stainless steel tubes.

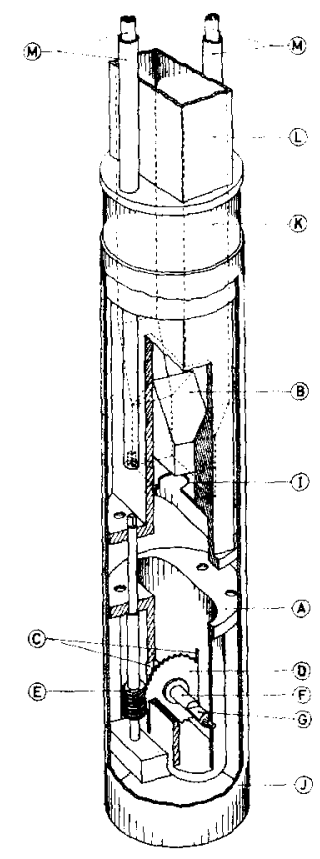

